\title{
Successful resuscitation of refractory ventricular fibrillation with double sequence defibrillation
}

\author{
SungJoon Park, Jung-Youn Kim, Young-Duck Cho, Eusun Lee, Bosun Shim, Young-Hoon Yoon \\ Department of Emergency Medicine, Korea University Guro Hospital, Seoul, Korea
}

In cardiac arrest, if the initial rhythm is ventricular fibrillation (VF) or pulseless ventricular tachycardia, the survival rates are high and good neurologic outcomes are expected. However, the mortality rate increases when refractory ventricular fibrillation (RVF) occurs. We report a case of RVF that was successfully resuscitated with double sequence defibrillation (DSD). A 51-year-old man visited the emergency department with chest pain. The initial electrocardiography showed markedly elevated ST-segment on V1-V5 leads, and VF arrest occurred. Although 10 defibrillations were administered over 20 minutes, there was no response. Two rounds of DSD were performed by placing additional pads on the patient's anterior-posterior areas and sequentially applying the maximum energy setting. The patient returned to spontaneous circulation and was discharged with cerebral performance category 1 after 14 days of hospital admission. Therefore, DSD could be an option for treatment and termination of RVF.

Key Words: advanced cardiac life support; defibrillators; survival rate; ventricular fibrillation

When ventricular fibrillation (VF) or pulseless ventricular tachycardia is the initial rhythm, survival rates and neurologic outcomes are better in both out-of-hospital cardiac arrest (OHCA) and in-hospital cardiac arrest (IHCA) cases [1]. For refractory VF that does not respond to defibrillation, the survival rate is low and the neurologic outcome is poor [2]. However, there is currently no clear definition of refractory $\mathrm{VF}$, and the term is typically used for cases where VF does not respond to three consecutive defibrillations [3]. To date, several methods have been implemented to treat refractory VF, although there is no gold standard of treatment.

Double sequence defibrillation (DSD) is an effective treatment for refractory VF. The DSD approach uses two sets of defibrillation pads, one for the anterior-apical (AA) area and the other for the anterior-posterior (AP) area (Figure 1). Two defibrillators are manually activated at their maximum energy setting. There are multiple techniques for delivering the shock for DSD and allow a delay of 1-2 seconds between sequential shocks or administer shocks almost simultaneously.

To date, all existing studies have been conducted on OHCA, most of which were performed by emergency medical technicians at the pre-hospital level [4-6]. There are no current reports of DSD to terminate refractory VF in IHCA. We report one case of refractory VF that occurred in the hospital and did not respond to standard defibrillation but was successfully treated

\section{Case Report}

Received: March 18, 2020

Revised: June 12, 2020

Accepted: July 27, 2020

Corresponding author Young-Hoon Yoon Department of Emergency Medicine, Korea University Guro Hospital, 148 Gurodong-ro, Guro-gu, Seoul 08308, Korea

Tel: +82-2-2626-1561

Fax: +82-2-2626-1562

E-mail:yyh71346@naver.com

Copyright () 2021 The Korean Society of Critical Care Medicine

This is an Open Access article distributed under the terms of Creative Attributions Non-Commercial License (https:// creativecommons.org/li-censes/by-nc/4.0/) which permits unrestricted noncommercial use, distribution, and reproduction in any medium, provided the original work is properly cited. 

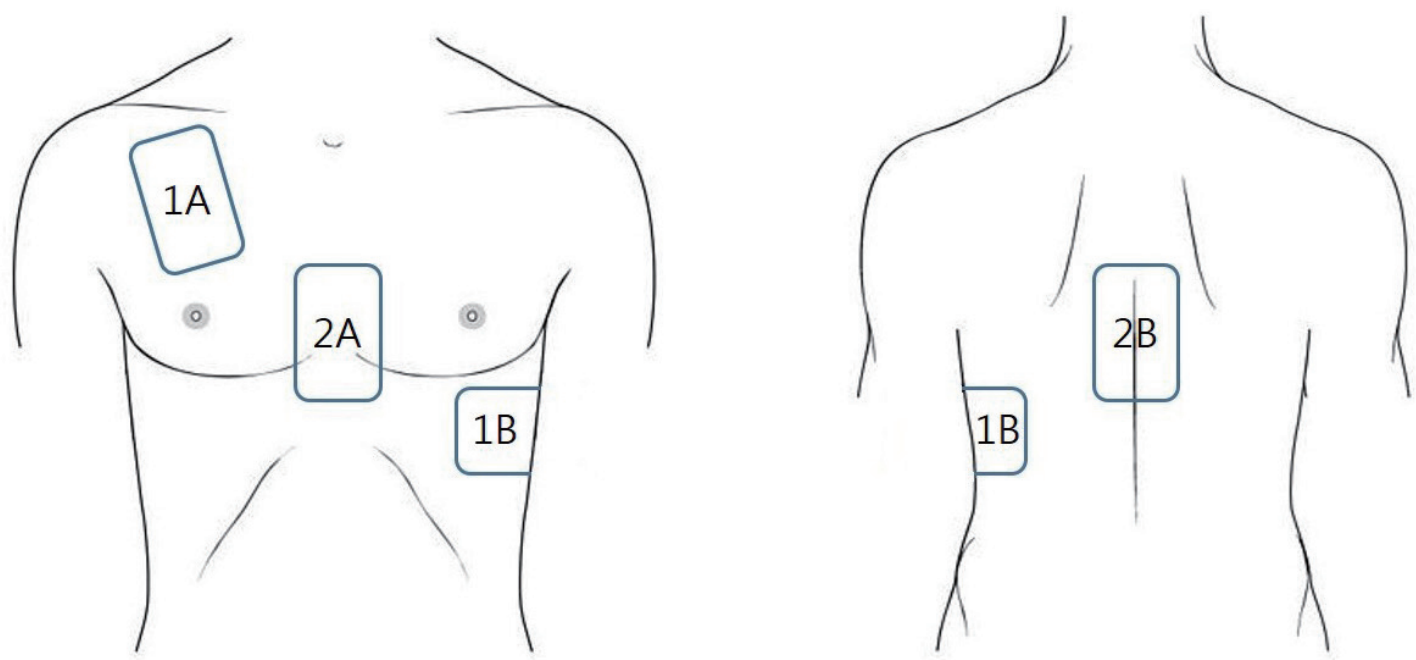

Figure 1. Approximate positions of defibrillation pads for double sequence defibrillation.

with DSD. To our knowledge, this is the first case to implement DSD for terminating refractory VF in IHCA.

\section{CASE REPORT}

A 51-year-old man visited the emergency department (ED) with chest pain. The pain had started 50 minutes prior to his visit, as he was going to sleep. He experienced chest heaviness with shortness of breath and broke out in a cold sweat but did not have radiating pains. When he arrived at the ED, his blood pressure was $114 / 71 \mathrm{~mm} \mathrm{Hg}$, heart rate was 91 beats per minute, respiratory rate was 20 breaths per minute, and body temperature was $36.0^{\circ} \mathrm{C}$. An initial electrocardiography (EKG) was captured and showed markedly elevated ST-segments on V1V5 leads.

Half an hour after he arrived in the ED, VF occurred while he was being prepared for emergency coronary angiography and percutaneous coronary intervention. After a $150 \mathrm{~J}$ defibrillation using a Philips HeartStart MRx (Philips Healthcare, Bothell, WA, USA) defibrillator and one cycle of cardiopulmonary resuscitation, spontaneous circulation returned. However, 3 minutes later, VF arrest reoccurred. Another $150 \mathrm{~J}$ defibrillation was administered, but there was no response; a second defibrillation of an additional $200 \mathrm{~J}$ defibrillation was applied. According to the Advanced Cardiac Life Support guidelines, the pulse and EKG rhythm were assessed every 2 minutes, and $1 \mathrm{mg}$ of epinephrine was administered via intravenous line every 3 minutes. Due to ongoing VF, $300 \mathrm{mg}$ and 150 mg amiodarone was administered at the third and fifth defibrillation rounds. Although 10 rounds of defibrillation with
$200 \mathrm{~J}$ were applied over 20 minutes, there was no response. Therefore, DSD was performed by placing additional pads on the patient and using another defibrillator, the Zoll M series (Zoll Medical, Chelmsford, MA, USA), sequentially on the patient's AP area at $200 \mathrm{~J}$ of energy, with small delays of 1-2 seconds between the two defibrillations. The patient returned to spontaneous circulation after DSD was administered twice.

The patient showed total occlusion at the left anterior descending coronary artery on coronary angiography, and percutaneous coronary intervention was performed. He was admitted to the intensive care unit with therapeutic hypothermia. After 14 days of hospital admission, he was discharged with cerebral performance category 1 and showed no other complications.

\section{DISCUSSION}

While existing DSD studies have been conducted on refractory VF from OHCA, this case shows that DSD in refractory VF from IHCA is also effective. Currently, there are debates on whether DSD is an effective approach, and several studies have shown that DSD does not affect survival rates or neurologic outcomes $[5,6]$. However, these studies implemented DSD as the last method after using standard defibrillation continuously. According to a study by Cheskes et al. [4] when DSD was implemented within four to eight attempts of defibrillation, it significantly improved the return of spontaneous circulation rates.

Although there is no clear mechanism for how DSD terminates refractory VF, there are several hypotheses. The first 
shock causes the current flow of the myocardium to lower the threshold of defibrillation so that the second shock can overcome the defibrillation threshold (threshold theory). Since cardiac muscle fiber is suitable for the direction of current flow for electrical stimulation, current flow with different vectors increases the success of defibrillation (vector theory). Larger individuals require more energy to terminate VF because not enough energy is delivered to the myocyte through the chest wall. DSD can cause defibrillation by providing increased energy delivery (weight-based therapy) [4-6]. To date, no study has assessed implementation and efficiency of DSD, which can be applied in many areas, such as determining how to apply two sets of pads to the patient, the amount of energy for the most efficient defibrillation dose, whether DSD should be implemented simultaneously or subsequently, or how much of a delay should be included in the procedure. Cheskes et al. [4] used AEDs (Zoll AED Plus, Zoll Medical) and defibrillators (LIFEPAK 15; Medtronic Physio-Control, Redmond, WA, USA) by attaching pads to the AA and AP areas to implement defibrillation in a rapid, sequential manner. However, they did not indicate how much energy was used for defibrillation [4]. Emmerson et al. [5] used a defibrillator (LIFEPAK 15, Medtronic Physio-Control) that provided a biphasic $360 \mathrm{~J}$ waveform by attaching pads to the AA and AP areas. They used the maximum energy setting of $360 \mathrm{~J}$ for each defibrillator to provide two sequential shocks at approximately 3-4 seconds apart. Ross et al. [6] used a defibrillator (Zoll X series, Zoll Medical) by attaching one of the pads to the AP area and the other to the right of the sternum over the apex and delivered shock simultaneously using the maximum energy setting of biphasic $200 \mathrm{~J}$.

In refractory $\mathrm{VF}$ that is not responding to persistent standard defibrillation, using venous-arterial extra-corporeal membrane oxygenation (ECMO), if available, is the most effective way to improve the survival rate [7]. When ECMO is possible, it requires many hours of effort [8]. Based on our results, DSD can be used as a bridge to ECMO or as a final option to terminate refractory VF. Because only a few case reports and retrospective observation studies are currently available, further randomized controlled studies are needed to confirm our results and observations.

\section{CONFLICT OF INTEREST}

No potential conflict of interest relevant to this article was reported.

\section{ORCID}

SungJoon Park https://orcid.org/0000-0001-6897-8740

Jung-Youn Kim

Young-Duck Cho

Eusun Lee

Bosun Shim

Young-Hoon Yoon https://orcid.org/0000-0001-8368-808X https://orcid.org/0000-0002-0213-311X https://orcid.org/0000-0001-6424-9946 https://orcid.org/0000-0003-4839-6588 https://orcid.org/0000-0002-1916-2080

\section{AUTHOR CONTRIBUTIONS}

Conceptualization, Project administration, \& Visualization: JYK, YDC, EL, BS. Writing-original draft: SungJoon Park. Writing-review \& editing: YHY.

\section{REFERENCES}

1. Benjamin EJ, Blaha MJ, Chiuve SE, Cushman M, Das SR, Deo $\mathrm{R}$, et al. Heart disease and stroke statistics-2017 update: a report from the American Heart Association. Circulation 2017; 135:e146-603.

2. Sakai T, Iwami T, Tasaki O, Kawamura T, Hayashi Y, Rinka H, et al. Incidence and outcomes of out-of-hospital cardiac arrest with shock-resistant ventricular fibrillation: data from a large population-based cohort. Resuscitation 2010;81:956-61.

3. Soar J, Nolan JP, Böttiger BW, Perkins GD, Lott C, Carli P, et al. European Resuscitation Council Guidelines for Resuscitation 2015: section 3. Adult advanced life support. Resuscitation 2015;95:100-47.

4. Cheskes S, Wudwud A, Turner L, McLeod S, Summers J, Morrison LJ, et al. The impact of double sequential external defibrillation on termination of refractory ventricular fibrillation during out-of-hospital cardiac arrest. Resuscitation 2019;139: 275-81.

5. Emmerson AC, Whitbread M, Fothergill RT. Double sequential defibrillation therapy for out-of-hospital cardiac arrests The London experience. Resuscitation 2017;117:97-101.

6. Ross EM, Redman TT, Harper SA, Mapp JG, Wampler DA, Miramontes DA. Dual defibrillation in out-of-hospital cardiac arrest: a retrospective cohort analysis. Resuscitation 2016;106:14-7.

7. Coppler PJ, Abella BS, Callaway CW, Chae MK, Choi SP, Elmer J, et al. Variability of extracorporeal cardiopulmonary resuscitation utilization for refractory adult out-of-hospital cardiac arrest: an international survey study. Clin Exp Emerg Med 2018;5:100-6.

8. Park JH, Song KJ, Shin SD, Ro YS, Hong KJ. Time from arrest to extracorporeal cardiopulmonary resuscitation and survival after out-of-hospital cardiac arrest. Emerg Med Australas 2019;31:1073-81. 